\title{
Common Carotid Artery Volume Flow: A Comparison Study between Ultrasound Vector Flow Imaging and Phase Contrast Magnetic Resonance Imaging
}

\author{
Andreas Hjelm Brandt ${ }^{1, *}$, Jacob Bjerring Olesen ${ }^{2}$, Ramin Moshavegh ${ }^{2}$, Jørgen Arendt Jensen ${ }^{3}$, \\ Michael Bachmann Nielsen 1,4 (D) and Kristoffer Lindskov Hansen 1,4 \\ 1 Department of Diagnostic Radiology, Rigshospitalet, Copenhagen University Hospital, \\ 2100 Copenhagen, Denmark; mbn@dadlnet.dk (M.B.N.); lindskov@gmail.com (K.L.H.) \\ 2 Bk Medical Aps, 2730 Herlev, Denmark; JBOlesen@bkmedical.com (J.B.O.); \\ RMoshavegh@bkmedical.com (R.M.) \\ 3 Center for Fast Ultrasound Imaging, Department of Health Technology, Technical University of Denmark, \\ 2800 Lyngby, Denmark; jaj@elektro.dtu.dk \\ 4 Department of Clinical Medicine, University of Copenhagen, 2200 Copenhagen, Denmark \\ * Correspondence: andreas.hjelm.brandt.02@regionh.dk
}

check for

updates

Citation: Brandt, A.H.; Olesen, J.B.; Moshavegh, R.; Jensen, J.A.; Nielsen, M.B.; Hansen, K.L. Common Carotid Artery Volume Flow: A Comparison Study between Ultrasound Vector Flow Imaging and Phase Contrast Magnetic Resonance Imaging. Neurol. Int. 2021, 13, 269-278. https:// doi.org/10.3390/neurolint13030028

Academic Editor: O-ki Kwon

Received: 18 May 2021

Accepted: 20 June 2021

Published: 23 June 2021

Publisher's Note: MDPI stays neutral with regard to jurisdictional claims in published maps and institutional affiliations.

Copyright: (c) 2021 by the authors. Licensee MDPI, Basel, Switzerland. This article is an open access article distributed under the terms and conditions of the Creative Commons Attribution (CC BY) license (https:/ / creativecommons.org/licenses/by/ $4.0 /)$.

\begin{abstract}
Volume flow estimation in the common carotid artery (CCA) can assess the absolute hemodynamic effect of a carotid stenosis. The aim of this study was to compare a commercial vector flow imaging (VFI) setup against the reference method magnetic resonance phase contrast angiography (MRA) for volume flow estimation in the CCA. Ten healthy volunteers were scanned with VFI and MRA over the CCA. VFI had an improved precision of $19.2 \%$ compared to MRA of $31.9 \%$ $(p=0.061)$. VFI estimated significantly lower volume flow than MRA (mean difference: $63.2 \mathrm{~mL} / \mathrm{min}$, $p=0.017)$, whilst the correlation between VFI and MRA was strong $\left(R^{2}=0.81, p<0.0001\right)$. A BlandAltman plot indicated a systematic bias. After bias correction, the percentage error was reduced from $41.0 \%$ to $25.2 \%$. This study indicated that a VFI setup for volume flow estimation is precise and strongly correlated to MRA volume flow estimation, and after correcting for the systematic bias, VFI and MRA become interchangeable.
\end{abstract}

Keywords: volume flow; vector flow imaging; phase contrast magnetic resonance imaging; common carotid artery

\section{Introduction}

Appoximately $85 \%$ of all strokes are caused by ischemia, while $15 \%$ are initiated by hemodynamically significant stenosis of the carotid artery [1,2]. Volume flow quantification of the common carotid artery (CCA) can assess the absolute hemodynamic effect of a carotid stenosis and can be used for monitoring cerebral blood flow after carotid endarterectomy or carotid stenting stenosis [3-5].

Phase contrast magnetic resonance imaging angiografi (MRA) and Doppler ultrasound (US) are commonly used for measuring cerebral blood flow [6]. Phase contrast MRA is considered the gold standard for non-invasive cerebral blood flow measurement; however, the estimation of CCA volume flow with MRA is time consuming, the technique is nonmobile, and the evaluation is not performed in real-time [7]. Doppler US is the first choice for carotid flow evaluation, as it is fast, bedside-available, and estimates flow in realtime. While color Doppler is a qualitative method for stenosis assessment in the CCA, spectral Doppler US can provide the CCA volume flow by measuring the mean velocity multiplied with the lumen area found with B-mode imaging. However, spectral Doppler US velocity estimation is angle-dependent and requires manual angle correction $[8,9]$. Furthermore, Doppler angle correction based on a single angle is insufficient, since in-vivo flow often presents several flow directions [10,11]. Additionally, the spectral broadening 
effect is ignored, even though spectral broadening causes velocity estimation error at any insonation angle [11-14]. Several Doppler US studies have investigated the volume flow of carotid arteries; however, evaluation of velocity is still considered the standard method for carotid flow assessment, e.g., for carotid stenosis [1,15-17].

Ultrasound vector flow imaging (VFI) is an angle-independent technique for vector velocity estimation [18]. VFI estimates both the axial and the transverse velocity component, while conventional Doppler US only estimates the axial velocity. Given both perpendicular velocities, the vector velocity can be estimated [19]. VFI has been validated with MRA for volume flow estimation in the CCA and with dilution techniques for volume flow in the ascending aorta and arteriovenous fistula [20-23]. VFI volume flow estimation in the CCA has previously only been conducted in experimental setups with a noncommercial US scanner [20,24].

The aim of this study was to compare the commercial VFI setup for CCA volume flow with the reference MRA method. The hypothesis was that VFI can estimate $\mathrm{z}$ similar volume flow as MRA in healthy volunteers.

\section{Materials and Methods}

Ten healthy volunteers (eight males and two females, mean age 32.2 years, range $25-52$ years) with no history of cardiac, vascular, or neurologic disease were included after informed consent, with approval obtained from the National Committee on Biomedical Research Ethics (journal no. H-1-2014-FSP-072). Both the left and right CCAs were scanned with VFI in one session. Within the hour before or after the ultrasound examination, MRA recordings of both CCAs of each volunteer for volume flow estimation were obtained. MRA and VFI estimations were performed with the volunteer in the supine position after at least $10 \mathrm{~min}$ of rest before each measurement. In a recent paper, MRA and VFI datasets were used for analysis of peak systolic velocities in the CCA [25].

A conventional ultrasound scanner equipped with a VFI (BK3000, BK Medical Aps, Herlev, Denmark) and a linear probe with a frequency range of 8-2 MHz (8L2, BK Medical Aps, Herlev, Denmark) was used to obtain VFI data. VFI was displayed in real-time at $30 \mathrm{~Hz}$ in 2D as color-coded pixels superimposed onto the B-mode images. Each color-coded pixel contained quantitative information about the direction and velocity magnitude. Flow was given within a color box adjusted to cover the lumen of the carotid artery with arrows overlaid on the color map to ease the immediate interpretation of the VFI flow data. The pulse repetition frequency was adjusted to the highest velocities to prevent aliasing. To avoid blooming artefacts, wall filter and color gain were set for optimal filling of the vessel by the operator. The transducer was positioned over the longitudinal center line of the vessel in the image plane, where the CCA had the widest diameter with the tunica initma visible at both the superficial and deep vessel walls. VFI recordings were processed offline in MATLAB (Mathworks, Natick, MA, USA) using an in-house developed algorithm for volume flow estimation. The operator placed two markers at the tunica intima on each side of the CCA. Assuming a circular vessel geometry and a circular symmetric flow, the volume flow was estimated along a line drawn between the two points by integration over the entire flow profile of the cross-sectional area, as described previously [26] (Figure 1). The volume flow was given in milliliters per minute and calculated from a minimum of 150 frames corresponding to four to five heartbeats of VFI data. Each CCA was evaluated twice in the same session for precision analyses. Volume flow calculations of the VFI data were performed by a radiologist with five years of VFI experience (A.H.B.) blinded to the corresponding MRA estimates. 


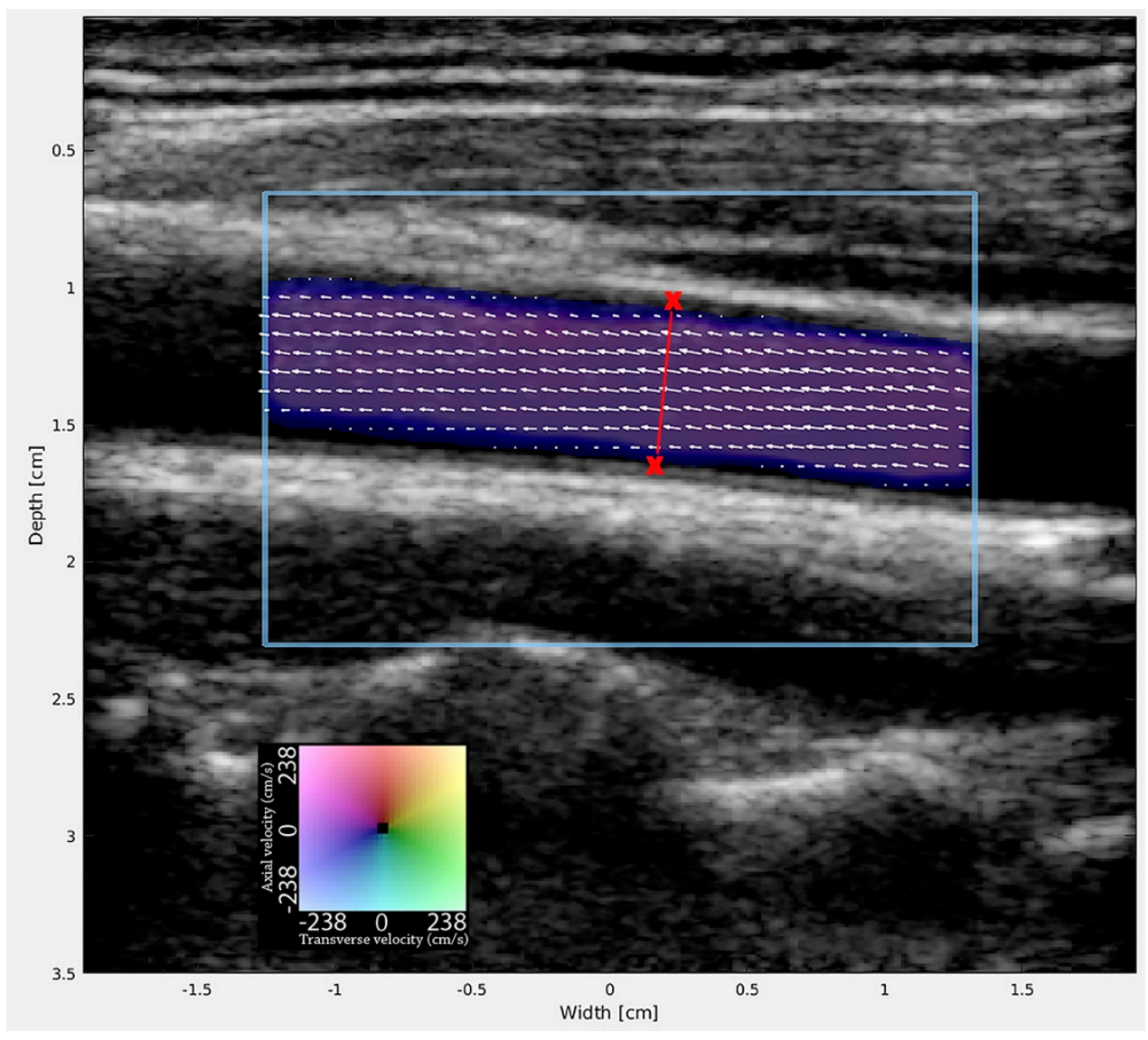

Figure 1. The VFI estimation setup in the CCA. Volume flow was found by integrating the VFI data along a line perpendicular to the long axis of the CCA. The line was drawn between two markers set by the operator at the intima of the vessel. The direction and velocity magnitude of the blood flow are given by the color wheel and indicated by the superimposed vector arrows.

All MRA measurements were performed within $1 \mathrm{~h}$ before or after the ultrasound examination. However, one volunteer was scanned $24 \mathrm{~h}$ after the VFI scan due to technical issues with the MR scanner. All MRA scans were performed with a 1.5-T MR scanner (Magnetom Avanto, Siemens, Erlangen, Germany). An electrocardiography gated phase contrast sequence using a head and neck coil (Neck Coil, Siemens, Erlangen, Germany) was used to estimate the through-plane velocities of the CCA. The sequence had a repetition time of $42 \mathrm{~ms}$, an echo time of $3 \mathrm{~ms}$, a flip angle $20^{\circ}$, a pixel resolution of $1.1 \times 1.1 \mathrm{~mm}$ in an image of $216 \times 256$ pixels, a slice thickness of $5 \mathrm{~mm}$, and a maximum velocity encoding of $\pm 1.0 \mathrm{~m} / \mathrm{s}$. For orientation, a 2D time-of-flight sequence with similar resolution was acquired parallel to the applied flow sequence (Figure 2). A radiologist with 15 years of experience (K.L.H.) performed the MRA examination. Each CCA was evaluated twice in the same session for precision analyses; however, due to an error the estimation for the first volunteer, evaluation was only performed once. 


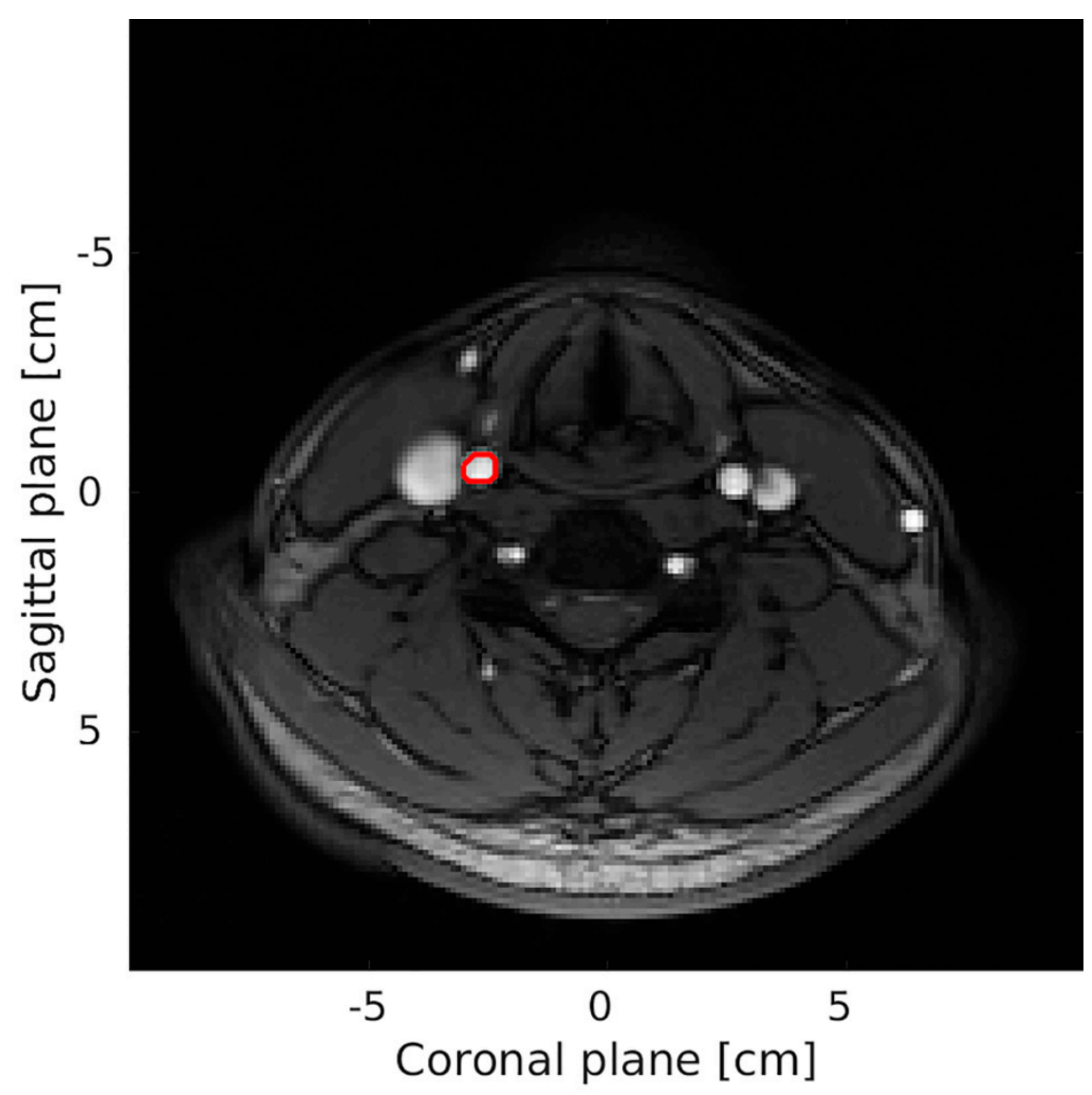

Figure 2. Transverse 2D time-of-flight sequence of the neck obtained with MRA. An example of volume flow of the right CCA was found within the region of interest (marked red). The MRA volume flow was found from a corresponding through-plane phase contrast MRA sequence (not shown).

The VFI and MRA volume flow estimations were performed at the same section of the CCA approximately $2 \mathrm{~cm}$ downstream from the bifurcation perpendicular to the long axis of the carotid artery. The MRI measurements were processed offline in MATLAB by an in-house developed algorithm. The CCA was pointed out manually and then a boundary detection algorithm, based on the MRA pixel intensity, located the outer contours of the vessel as the region of interest (ROI). All pixels within the ROI were used for the volume flow estimation [27]. All MRA volume flow calculations were performed by J.B.O., blinded to the corresponding VFI estimates.

For the statistical analysis, the precision $P$ was found for each method corresponding to two standard deviations (STDs) of the difference between replicate measurements $a$ and $b$ of a method $x$, divided by the mean, and given as a percentage:

$$
P=\frac{2 * \operatorname{STD}\left(x_{n}^{a}-x_{n}^{b}\right)}{\bar{x}} * 100,
$$

where $n$ is the number of replicated experiments, and $\bar{x}$ is the average of measurements $a$ and $b$.

A linear regression analysis, as well as a Bland-Altman analysis, were used for agreement analyses between VFI and MRA. The first of the two replicated measurements was used for the comparisons. From the limit of agreement (LOA) of the Bland-Altman analysis, the percentage error $P E$ was calculated. 
The PE for the comparison of two methods $x$ and $y$ (VFI and MRA) was calculated similarly to the calculation of precision for replicate measurements, i.e., two STDs of the difference divided by the mean of the two methods and given as a percentage:

$$
P E=\frac{2 * S T D\left(x_{n}-y_{n}\right)}{(\bar{x}+\bar{y}) / 2} * 100,
$$

where $n$ is the volunteer number, and $\bar{x}$ and $\bar{y}$ are the average values obtained for methods $x$ and $y$. Thus, the precision $P$ and $P E$ verged toward 0 for perfectly replicated measurements and perfect comparisons. The systematic bias was calculated from the linear regression analysis and applied to VFI data for calculation of a corrected PE, as carried out by Hansen et al. [22].

The expected LOA for the Bland-Altman plot of the two methods $x$ and $y$ can be calculated as:

$$
\left.S T D_{x+y}=\sqrt{\left(S T D_{x}^{2}\right.}+S T D_{y}^{2}\right),
$$

where STD is the standard deviation of methods $x$ and $y$ in comparison. Instead of $S T D$, the calculated precision $P$ was used, as per previous research $[23,28]$.

Datasets recorded on the right and left sides were pooled to access a larger amount of data for the comparison. The presence of a statistical difference between the precision of each method, as well as compared to the VFI and MRA estimates, was evaluated with paired $t$-tests. A $p$-value of $<0.05$ was considered statistically significant. Statistical analyses and data management were performed with Excel (Microsoft Excel (Microsoft Corporation, Redmond, WA, USA), MATLAB, and IBM SPSS Statistics 22 (SPSS Inc., Chicago, IL, USA).

\section{Results}

An overview of the collected data is given in Table 1. The VFI volume flow was significantly different to the MRA volume flow when comparing the first of the two replicated measurements $(p=0.017)$. The precision estimates (Equation (1)) for VFI and MRA were $19.2 \%$ and $31.9 \%(p=0.061)$, respectively, which corresponded to an expected LOA using Equation (3) of $37.2 \%$. The mean differences, lower/upper LOA, PE (Equation (2)), and correlation coefficient for the comparisons between VFI and MRA are listed in Table 2 and illustrated in Figure 3. The Bland-Altman plot indicated a systematic bias. After bias correction of the VFI data using the equation for the line of best fit $(y=1.39 x-84.2)$, the percentage error between VFI and MRA reduced from $41.0 \%$ to $25.2 \%$.

Table 1. Mean and range of the replicated MRA and VFI estimations. (1) represents the first acquisition and (2) the second.

\begin{tabular}{ccccc}
\hline & $\begin{array}{c}\text { MRA (1) } \\
(\boldsymbol{n}=\mathbf{2 0})\end{array}$ & $\begin{array}{c}\text { MRA (2) } \\
(\boldsymbol{n}=\mathbf{1 8})\end{array}$ & $\begin{array}{c}\text { VFI (1) } \\
(\boldsymbol{n}=\mathbf{2 0})\end{array}$ & $\begin{array}{c}\text { VFI (2) } \\
(\boldsymbol{n}=\mathbf{2 0})\end{array}$ \\
\hline Mean (mL/min) & 447.0 & 421.3 & 380.3 & 385.6 \\
\hline Range (mL/min) & $182.5-1111.4$ & $280.6-696.8$ & $260.4-816.6$ & $235.2-753.6$ \\
\hline
\end{tabular}

Table 2. Mean differences, lower/upper limits of agreements (LOAs), percentage errors (PEs), and correlation coefficients for comparisons between VFI and MRA.

\begin{tabular}{lccccc}
\hline & $\begin{array}{c}\text { Mean } \\
\text { Difference } \\
(\mathbf{m L} / \mathbf{m i n})\end{array}$ & $\begin{array}{c}\text { Lower LOA } \\
(\mathbf{m L} / \mathbf{m i n})\end{array}$ & $\begin{array}{c}\text { Upper LOA } \\
(\mathbf{m L} / \mathbf{m i n})\end{array}$ & $\begin{array}{c}\text { Correlation } \\
\text { Coefficient } \\
\left(\boldsymbol{R}^{\mathbf{2}}\right)\end{array}$ & $\begin{array}{c}\text { PE (\%) } \\
\text { PE after Correction of } \\
\text { Systematic Bias (\%) }\end{array}$ \\
\hline MRA vs. VFI & $\begin{array}{c}63.2(95 \% \mathrm{CI}: \\
-113.4 \text { to } 12.9)\end{array}$ & $\begin{array}{c}-148.8(95 \% \mathrm{CI}: \\
-235.9 \text { to } 61.7)\end{array}$ & $\begin{array}{c}275.1(95 \% \mathrm{CI}: \\
188.0-362.2)\end{array}$ & $0.81(p<0.0001)$ & 41.0 \\
\hline
\end{tabular}



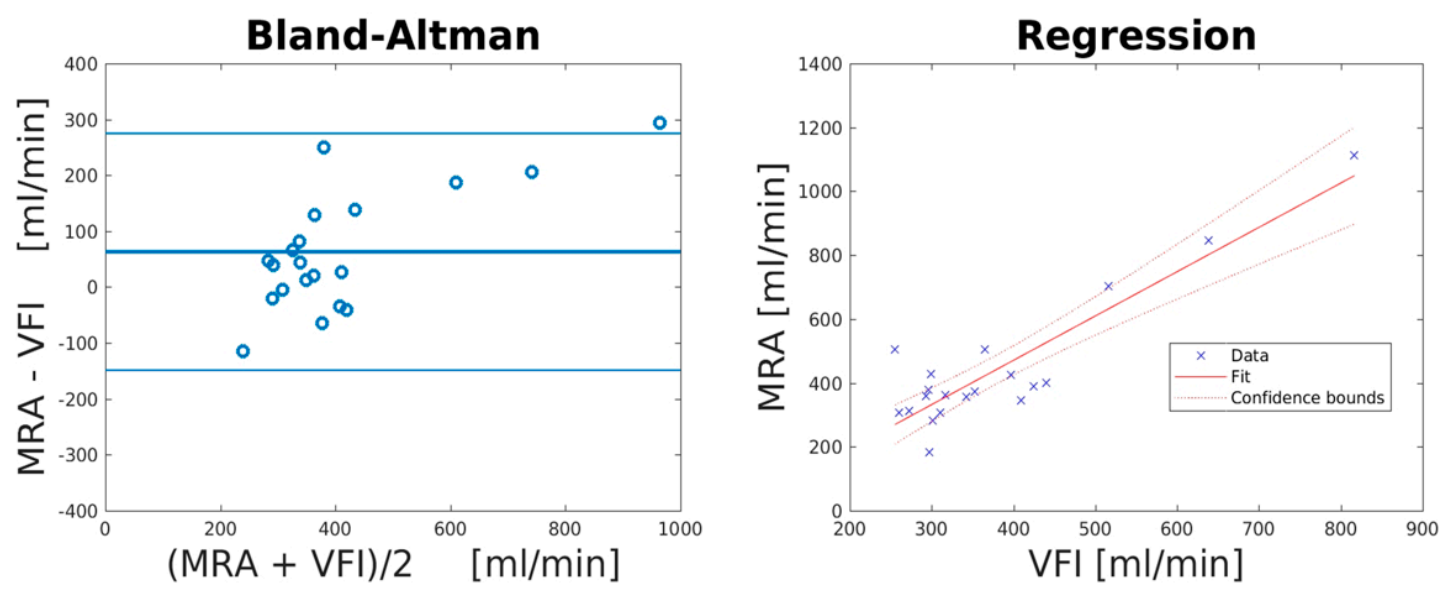

Figure 3. Volume flow estimations with VFI and MRA of the CCA evaluated with Bland-Altman and linear regression plots. The lines in the Bland-Altman plot (left) correspond to the mean bias and LOA, while the lines in the linear regression plot (right) correspond to line of best fit and confidence bounds. Notice a larger positive bias for higher volume flows, indicating a systematic bias.

\section{Discussion}

This study evaluated the commercial VFI setup against MRA, the reference method for volume flow estimation in the CCA. VFI measured significantly lower volume flow compared to MRA, with indication of an improved precision. The correlation between MRA and VFI was strong. To test if the two methods are interchangeable, the LOA of a BlandAltman plot in a comparison study should not be wider than the expected LOA, or below $30 \%$ as recommended by Critchley et al. [29]. The PE was above the excepted LOA and 30\%, and therefore, VFI and MRA cannot be considered interchangeable. However, the BlandAltman plot indicated a systematic bias. After bias correction, the reduced PE was below $30 \%$, as well as the expected LOA, suggesting that the two methods are interchangeable if the VFI data are corrected. Hence, this study indicates that a commercially available VFI setup for volume flow estimation after bias correction is interchangeable with the reference method MRA and may be ready for volume flow evaluation in a clinical context.

Blood flow volume measurement can be estimated with conventional Doppler US; however, conflicting results have been published concerning the accuracy of both in vitro and in vivo estimations. In vitro experiments have shown a reasonable accurate measurements of blood volume flow in the flow range of $100-1000 \mathrm{~mL} / \mathrm{min}$ with an average root mean square error of $37.2-81.1 \mathrm{~mL} / \mathrm{min}$ between a flow phantom and several Doppler ultrasound systems, while in vivo experiments of the carotid arteries have shown Doppler US volume flow estimation to overestimate $22-46 \%$ compared to MRA $[4,30]$.

VFI volume flow estimation with a non-commercial setup has, in previous studies, shown a strong correlation $(R=0.91)$ with MRA [20]. Volume flow estimation with a commercially available VFI setup as the one applied in this study has previously been investigated with a different algorithm for volume flow calculation in arteriovenous fistulas and the ascending aorta $[22,31]$. The algorithm for volume flow estimation used in these studies assumed a circular symmetric and parabolic flow profile, while the algorithm used in this study only relied on circular symmetric flow. The obtained VFI volume flow estimations presented in the previous studies were not interchangeable with the compared methods, i.e., thermodilution and Doppler US [22,31].

In diseased vessels with stenotic segments, the velocity increases and the volume flow decreases $[17,32]$. While, the intima media thickness in the common carotid artery has been used as a surrogate marker for atherosclerosis [33], the preferred method for stenosis assessment using ultrasound is velocity evaluation within the stenotic vessel segment [34]. However, due to calcified plaques, the degree of stenosis from velocity assessments can be 
difficult to estimate in some patients, and volume flow estimation with VFI downstream of the stenosis could be an alternative measure [35].

The complexity of the flow also increases with stenoses, and can be assessed with spectral Doppler US by estimating spectral broadening or evaluating mosaic patterns with color Doppler [36,37]. An alternative to conventional Doppler for the assessment of flow complexity is VFI, whose angle can independently, instantaneously, and quantitatively estimate whether the flow is laminar or turbulent [38]. In both the CCA and the superficial femoral artery, the flow changes induced by stenoses have been quantified with VFI and compared to digital subtraction angiography with a strong correlation [39,40]. VFI may improve stenosis grading by estimation of volume flow and assessment of flow complexity. All CCAs examined in this study had laminar flow. The VFI volume flow estimation algorithm applied in this study must therefore be examined on vessels with disturbed flow to explore the VFI method for patients with vessel disease.

VFI is not limited by the size or placement of the sample volume as with Doppler US. The placement of the sample volume and the manual applied angle correction in Doppler US evaluation add to the error in the velocity estimation and can be a reason for the low interobserver agreement found for conventional Doppler US [41-44]. VFI may be less operator dependent than conventional Doppler US, since no manual angle correction is applied [45]. Recently, VFI has been shown to have improved inter- and intraobserver agreement and to be less operator experience dependent compared to Doppler US [46]. Doppler US has previously been compared to MRA and has shown to estimate significantly different volume flow estimates [30]. Meanwhile, the commercial VFI setup has shown to be more precise than Doppler US for peak systolic velocity evaluation in the CCA, a study comparing the commercial VFI setup for volume flow estimation against Doppler US is missing [25].

Quantitative assessment of carotid and vertebral volume flow has been suggested as an estimate of total cerebral blood flow and can be clinically useful in several of cerebrovascular diseases. Besides evaluating carotid stenosis, the presence of collateral pathways and associated conditions, investigation of vertebrobasilar insufficiency, and estimation of the shunt volume in cerebral arteriovenous malformations have been suggested [7]. An accurate measurement technique is therefore of great importance. VFI might be more accurate than MRA for volume flow estimation, even though MRA is accepted as the gold standard for quantification of cerebral blood flow [47]. Therefore, VFI may be a new tool for total cerebral blood flow evaluation.

Some drawbacks of this study must be acknowledged. The small sample size is the most obvious limitation. Furthermore, the applied algorithm did not concern movement of the vessel during the cardiac cycle or displacement of the transducer during the scan. The lack of tracing the vessel wall may have caused an underestimation of the velocity profile. Moreover, volume flow estimation was not performed directly on the scanner, but rather processed offline. A fully automatic integrated method for volume flow assessment could ease the pursuit for a larger, more evidence-creating study. Only one operator performed the data collection and data analysis for VFI; hence, no interobserver variability was calculated. Furthermore, even though MRI is considered the gold standard for noninvasive volume flow estimation, the method underestimates the flow by $5-8 \%$ with a standard deviation of $11.2 \%$ for repeated measurements, which obviously could affect the comparison analyses [47]. Finally, alignment between MRA and VFI recordings was not carried out exactly, which will bias the comparison of velocities [48].

\section{Conclusions}

In healthy volunteers, VFI and MRA volume flow estimates of the CCA were strongly correlated, though VFI significantly underestimated the volume flow estimates. VFI had superior precision compared to MRA and was, after correction of the systematic bias, interchangeable with MRA. VFI may be a useful alternative for volume flow estimation in the CCA with bedside availability and a lower operational cost compared to MRA. 
Author Contributions: Conceptualization, A.H.B., J.B.O., R.M., J.A.J., M.B.N. and K.L.H.; methodology, A.H.B., J.B.O., R.M., J.A.J., M.B.N. and K.L.H.; software, R.M. and J.B.O.; validation, A.H.B., J.B.O., R.M. and K.L.H.; formal analysis, A.H.B. and K.L.H.; investigation, A.H.B., J.B.O., R.M., J.A.J., M.B.N. and K.L.H.; resources, A.H.B., J.B.O., R.M., J.A.J., M.B.N. and K.L.H.; data curation, A.H.B. and J.B.O.; writing-original draft preparation, A.H.B. and K.L.H.; writing-review and editing, A.H.B., J.B.O., R.M., J.A.J., M.B.N. and K.L.H.; visualization A.H.B., R.M., J.B.O. and K.L.H.; supervision, J.A.J., M.B.N. and K.L.H.; project administration, A.H.B. and K.L.H.; funding acquisition, A.H.B. All authors have read and agreed to the published version of the manuscript.

Funding: This research received no external funding.

Institutional Review Board Statement: The study was conducted according to the guidelines of the Declaration of Helsinki and approved by the Danish National Committee on Biomedical Research Ethics, protocol no. H-1-2014-FSP-072.

Informed Consent Statement: Informed consent was obtained from all subjects involved in the study.

Data Availability Statement: The data presented in this study are available on request from the corresponding author. The data are not publicly available due to privacy.

Acknowledgments: The authors wish to thank all participating healthy volunteers.

Conflicts of Interest: The author J.A.J. developed and patented the method Vector Flow Imaging and earns royalties for the selling of scanners with the Vector Flow Imaging option from BK medical. BK medical employs the authors J.B.O. and R.M. The other authors declare no conflicts of interest.

\section{References}

1. Kaszczewski, P.; Elwertowski, M.; Leszczynski, J.; Ostrowski, T.; Galazka, Z. Volumetric Carotid Flow Characteristics in Doppler Ultrasonography in Healthy Population Over 65 Years Old. J. Clin. Med. 2020, 9, 1375. [CrossRef]

2. Roger, V.L.; Go, A.S.; Lloyd-Jones, D.M.; Benjamin, E.J.; Berry, J.D.; Borden, W.B.; Bravata, D.M.; Dai, S.; Ford, E.S.; Fox, C.S.; et al. Heart disease and stroke statistics-2012 update: A report from the American Heart Association. Circulation 2012, 125, e2-e220.

3. Mitrasinovic, A.; Radak, S.; Kolar, J.; Aleksic, N.; Otasevic, P.; Popovic, M.; Radak, D. Color Doppler sonographic evaluation of flow volume of the internal carotid and vertebral arteries after carotid endarterectomy. J. Clin. Ultrasound 2010, 38, 238-243. [CrossRef] [PubMed]

4. Ho, S.S.Y.; Chan, Y.L.; Yeung, D.K.W.; Metreweli, C. Blood Flow Volume Quantification of Cerebral Ischemia. AJR Am. J. Roentgenol. 2002, 178, 551-556. [CrossRef]

5. Tanaka, H.; Watanabe, Y.; Nakamura, H.; Takahashi, H.; Arisawa, A.; Fujiwara, T.; Matsuo, C.; Tomiyama, N. Multiple blood flow measurements before and after carotid artery stenting via phase-contrast magnetic resonance imaging: An observational study. PLOS ONE 2018, 13, e0195099. [CrossRef]

6. Vernooij, M.W.; van der Lugt, A.; Ikram, M.A.; Wielopolski, P.A.; Vrooman, H.A.; Hofman, A.; Krestin, G.P.; Breteler, M.M. Total cerebral blood flow and total brain perfusion in the general population: The Rotterdam Scan Study. J. Cereb. Blood Flow Metab. 2008, 28, 412-419. [CrossRef]

7. Oktar, S.O.; Yucel, C.; Karaosmanoglu, D.; Akkan, K.; Ozdemir, H.; Tokgoz, N.; Tali, T. Blood-flow volume quantification in internal carotid and vertebral arteries: Comparison of 3 different ultrasound techniques with phase-contrast MR imaging. AJNR Am. J. Neuroradiol. 2006, 27, 363-369.

8. Stewart, S.F. Effects of transducer, velocity, Doppler angle, and instrument settings on the accuracy of color Doppler ultrasound. Ultrasound Med. Biol. 2001, 27, 551-564. [CrossRef]

9. Park, M.Y.; Jung, S.E.; Byun, J.Y.; Kim, J.H.; Joo, G.E. Effect of beam-flow angle on velocity measurements in modern Doppler ultrasound systems. AJR. Am. J. Roentgenol. 2012, 198, 1139-1143. [CrossRef]

10. Hansen, K.L.; Moller-Sorensen, H.; Kjaergaard, J.; Jensen, M.B.; Lund, J.T.; Pedersen, M.M.; Lange, T.; Jensen, J.A.; Nielsen, M.B. Intra-operative Vector Flow Imaging Using Ultrasound of the Ascending Aorta among 40 Patients with Normal, Stenotic and Replaced Aortic Valves. Ultrasound Med. Biol. 2016, 42, 2414-2422. [CrossRef]

11. Steel, R.; Ramnarine, K.V.; Davidson, F.; Fish, P.J.; Hoskins, P.R. Angle-independent estimation of maximum velocity through stenoses using vector Doppler ultrasound. Ultrasound Med. Biol. 2003, 29, 575-584. [CrossRef]

12. Yang, X.; Sun, C.; Anderson, T.; Moran, C.M.; Hadoke, P.W.; Gray, G.A.; Hoskins, P.R. Assessment of spectral Doppler in preclinical ultrasound using a small-size rotating phantom. Ultrasound Med. Biol. 2013, 39, 1491-1499. [CrossRef] [PubMed]

13. Hoskins, P.R. A comparison of single- and dual-beam methods for maximum velocity estimation. Ultrasound Med. Biol. 1999, 25, 583-592. [CrossRef]

14. Steinman, A.H.; Tavakkoli, J.; Myers, J.G., Jr.; Cobbold, R.S.; Johnston, K.W. Sources of error in maximum velocity estimation using linear phased-array Doppler systems with steady flow. Ultrasound Med. Biol. 2001, 27, 655-664. [CrossRef]

15. Scheel, P.; Ruge, C.; Petruch, U.R.; Schöning, M. Color duplex measurement of cerebral blood flow volume in healthy adults. Stroke 2000, 31, 147-150. [CrossRef] 
16. Likittanasombut, P.; Reynolds, P.; Meads, D.; Tegeler, C. Volume Flow Rate of Common Carotid Artery Measured by Doppler Method and Color Velocity Imaging Quantification (CVI-Q). J. Neuroimaging 2006, 16, 34-38. [CrossRef]

17. Grant, E.G.; Benson, C.B.; Moneta, G.L.; Alexandrov, A.V.; Baker, J.D.; Bluth, E.I.; Carroll, B.A.; Eliasziw, M.; Gocke, J.; Hertzberg, B.S.; et al. Carotid artery stenosis: Gray-scale and Doppler US diagnosis-Society of Radiologists in Ultrasound Consensus Conference. Radiology 2003, 229, 340-346. [CrossRef]

18. Jensen, J.A.; Munk, P. A new method for estimation of velocity vectors. IEEE Trans. Ultrason. Ferroelectr. Freq. Control. 1998, 45, 837-851. [CrossRef]

19. Jensen, J.A. A new estimator for vector velocity estimation. Ultrason. Ferroelectr. Freq. Control. IEEE Trans. 2001, 48, 886-894. [CrossRef]

20. Hansen, K.L.; Udesen, J.; Oddershede, N.; Henze, L.; Thomsen, C.; Jensen, J.A.; Nielsen, M.B. In vivo comparison of three ultrasound vector velocity techniques to MR phase contrast angiography. Ultrasonics 2009, 49, 659-667. [CrossRef]

21. Udesen, J.; Jensen, J.A. Investigation of transverse oscillation method. IEEE Trans. Ultrason. Ferroelectri. Freq. Control. 2006, 53, 959-971. [CrossRef]

22. Hansen, K.L.; Moller-Sorensen, H.; Kjaergaard, J.; Jensen, M.B.; Lund, J.T.; Pedersen, M.M.; Olesen, J.B.; Jensen, J.A.; Nielsen, M.B. Vector Flow Imaging Compared with Conventional Doppler Ultrasound and Thermodilution for Estimation of Blood Flow in the Ascending Aorta. Ultrasonic Imaging 2017, 39, 3-18. [CrossRef]

23. Brandt, A.H.; Jensen, J.; Hansen, K.L.; Hansen, P.; Lange, T.; Rix, M.; Jensen, J.A.; Lonn, L.; Nielsen, M.B. Surveillance for hemodialysis access stenosis: Usefulness of ultrasound vector volume flow. J. Vas. Access 2016, 17, 483-488. [CrossRef]

24. Holbek, S.; Ewertsen, C.; Bouzari, H.; Pihl, M.J.; Hansen, K.L.; Stuart, M.B.; Thomsen, C.; Nielsen, M.B.; Jensen, J.A. Ultrasonic 3-D Vector Flow Method for Quantitative In Vivo Peak Velocity and Flow Rate Estimation. IEEE Trans. Ultrason. Ferroelectri. Freq. Control. 2017, 64, 544-554. [CrossRef]

25. Brandt, A.H.; Hansen, K.L.; Ewertsen, C.; Holbek, S.; Olesen, J.B.; Moshavegh, R.; Thomsen, C.; Jensen, J.A.; Nielsen, M.B. A Comparison Study of Vector Velocity, Spectral Doppler and Magnetic Resonance of Blood Flow in the Common Carotid Artery. Ultrasound Med. Biol. 2018, 44, 1751-1761. [CrossRef] [PubMed]

26. Hansen, K.L.; Udesen, J.; Thomsen, C.; Jensen, J.A.; Nielsen, M.B. In vivo validation of a blood vector velocity estimator with MR angiography. IEEE Trans Ultrason. Ferroelectri. Freq. Control. 2009, 56, 91-100. [CrossRef] [PubMed]

27. Holbek, S.; Hansen, K.L.; Bouzari, H.; Ewertsen, C.; Stuart, M.B.; Thomsen, C.; Nielsen, M.B.; Jensen, J.A. Common Carotid Artery Flow Measured by 3-D Ultrasonic Vector Flow Imaging and Validated with Magnetic Resonance Imaging. Ultrasound Med. Biol. 2017, 43, 2213-2220. [CrossRef] [PubMed]

28. Moller-Sorensen, H.; Hansen, K.L.; Ostergaard, M.; Andersen, L.W.; Moller, K. Lack of agreement and trending ability of the endotracheal cardiac output monitor compared with thermodilution. Acta Anaesthesiol. Scand. 2012, 56, 433-440. [CrossRef]

29. Critchley, L.A.; Critchley, J.A. A meta-analysis of studies using bias and precision statistics to compare cardiac output measurement techniques. J. Clin. Monit. Comput. 1999, 15, 85-91. [CrossRef] [PubMed]

30. Hoyt, K.; Hester, F.A.; Bell, R.L.; Lockhart, M.E.; Robbin, M.L. Accuracy of volumetric flow rate measurements: An in vitro study using modern ultrasound scanners. J. Ultrasound Med. 2009, 28, 1511-1518. [CrossRef]

31. Hansen, P.M.; Olesen, J.B.; Pihl, M.J.; Lange, T.; Heerwagen, S.; Pedersen, M.M.; Rix, M.; Lonn, L.; Jensen, J.A.; Nielsen, M.B. Volume flow in arteriovenous fistulas using vector velocity ultrasound. Ultrasound Med. Biol. 2014, 40, 2707-2714. [CrossRef]

32. Ackroyd, N.; Gill, R.; Griffiths, K.; Kossoff, G.; Appleberg, M. Quantitative common carotid artery blood flow: Prediction of internal carotid artery stenosis. J. Vasc. Surg. 1986, 3, 846-853. [CrossRef]

33. Nezu, T.; Hosomi, N.; Aoki, S.; Matsumoto, M. Carotid Intima-Media Thickness for Atherosclerosis. J. Atheroscler. Thromb. 2016, 23, 18-31. [CrossRef]

34. Mortimer, R.; Nachiappan, S.; Howlett, D.C. Carotid artery stenosis screening: Where are we now? Br. J. Radiol. 2018, 90, 20170380. [CrossRef] [PubMed]

35. Morales, M.M.; Anacleto, A.; Filho, C.M.; Ledesma, S.; Aldrovani, M.; Wolosker, N. Peak Systolic Velocity for Calcified Plaques Fails to Estimate Carotid Stenosis Degree. Ann. Vasc. Surg. 2019, 59, 1-4. [CrossRef]

36. Stringer, D.A.; O’Halpin, D.; Daneman, A.; Liu, P.; Geary, D.F. Duplex Doppler sonography for renal artery stenosis in the post-transplant pediatric patient. Pediatr. Radiol. 1989, 19, 187-192. [CrossRef] [PubMed]

37. Hutchison, S.J.; Rosin, B.L.; Curry, S.; Chandraratna, P.A. Transesophageal Echocardiographic Assessment of Lesions of the Right Ventricular Outflow Tract and Pulmonic Valve. Echocardiography 1996, 13, 21-34. [CrossRef] [PubMed]

38. Pedersen, M.M.; Pihl, M.J.; Haugaard, P.; Hansen, K.L.; Lange, T.; Lonn, L.; Nielsen, M.B.; Jensen, J.A. Novel flow quantification of the carotid bulb and the common carotid artery with vector flow ultrasound. Ultrasound Med. Biol. 2014, 40, 2700-2706. [CrossRef] [PubMed]

39. Brandt, A.H.; Nguyen, T.; Gutte, H.; Holtmannspötter, M.; Moshavegh, R.; Jensen, J.A.; Nielsen, M.B.; Hansen, K.L. Vector Concentration used for Stenosis Assessment in the Carotid Artery before and after Carotid Stenting. In Proceedings of the 2019 IEEE International Ultrasonics Symposium (IUS), Glasgow, UK, 6-9 October 2019; pp. 348-351.

40. Hansen, K.L.; Hansen, P.M.; Ewertsen, C.; Lonn, L.; Jensen, J.A.; Nielsen, M.B. Vector Flow Imaging Compared with Digital Subtraction Angiography for Stenosis Assessment in the Superficial Femoral Artery-A Study of Vector Concentration, Velocity Ratio and Stenosis Degree Percentage. Ultrasound Int. Open 2019, 5, E53-E59. [CrossRef] 
41. Normahani, P.; Aslam, M.; Martin, G.; Standfield, N.J.; Jaffer, U. Variation in duplex peak systolic velocity measurement in a multi-site vascular service. Perfusion 2015, 30, 636-642. [CrossRef]

42. Corriveau, M.M.; Johnston, K.W. Interobserver variability of carotid Doppler peak velocity measurements among technologists in an ICAVL-accredited vascular laboratory. J. Vasc. Surg. 2004, 39, 735-741. [CrossRef] [PubMed]

43. Lui, E.Y.L.; Steinman, A.H.; Cobbold, R.S.C.; Johnston, K.W. Human factors as a source of error in peak Doppler velocity measurement. J. Vasc. Surg. 2005, 42, 972-979. [CrossRef]

44. Zierler, R.E.; Beach, K.W.; Bergelin, R.O.; Lal, B.K.; Moore, W.S.; Roubin, G.S.; Voeks, J.H.; Brott, T.G. Agreement between sitereported and ultrasound core laboratory results for duplex ultrasound velocity measurements in the Carotid Revascularization Endarterectomy versus Stenting Trial. J. Vasc. Surg. 2014, 59, 2-7. [CrossRef] [PubMed]

45. Pedersen, M.M.; Pihl, M.J.; Haugaard, P.; Hansen, J.M.; Hansen, K.L.; Nielsen, M.B.; Jensen, J.A. Comparison of real-time in vivo spectral and vector velocity estimation. Ultrasound Med. Biol. 2012, 38, 145-151. [CrossRef] [PubMed]

46. Brandt, A.H.; Moshavegh, R.; Hansen, K.L.; Bechsgaard, T.; Lönn, L.; Jensen, J.A.; Nielsen, M.B. Vector Flow Imaging Compared with Pulse Wave Doppler for Estimation of Peak Velocity in the Portal Vein. Ultrasound Med. Biol. 2018, 44, 593-601. [CrossRef]

47. Spilt, A.; Box, F.M.; van der Geest, R.J.; Reiber, J.H.; Kunz, P.; Kamper, A.M.; Blauw, G.J.; van Buchem, M.A. Reproducibility of total cerebral blood flow measurements using phase contrast magnetic resonance imaging. J. Magn. Reson Imaging 2002, 16, 1-5. [CrossRef]

48. Meyer, J.I.; Khalil, R.M.; Obuchowski, N.A.; Baus, L.K. Common carotid artery: Variability of Doppler US velocity measurements. Radiology 1997, 204, 339-341. [CrossRef] [PubMed] 